\title{
Práticas educativas sobre diversidade sexual no ambiente educacional: possível ou ainda uma utopia?
}

\author{
Clodoaldo Fernandes* \\ Ivonete Bueno dos Santos**
}

\section{Resumo}

O presente artigo, a partir de estudos de Louro (2004, 2007, 2010), Michel Foucault (2001a, 2001b), Moita Lopes (2006, 2008), dentre outros, propóe analisar, na materialidade linguístico-discursiva de alguns recortes advindos de três artigos sobre a diversidade sexual no contexto escolar, os efeitos de sentido que perpassam os seus principais pontos em comum e a recorrência de vozes que entrecruzam as práticas discursivas nesses trabalhos. Este estudo, de caráter qualitativo, de base indutiva e interpretativa, revela a necessidade de se empreenderem reflexôes acerca da sexualidade no espaço escolar, a partir de práticas educativas sobre a diversidade sexual.

Palavras-chave: diversidade sexual, educação, práticas discursivas.

Educational practices on sexual diversity in the educational context: possibility or utopia?

\begin{abstract}
This article, based on studies by Louro (2001, 2004, 2010), Michel Foucault (2001a; 2001b), Moita Lopes (2008) and others, sets out to discuss the linguistic-discursive materiality of certain excerpts from three articles about sexual diversity in the school context, the effects of meaning that permeate their main common points and the recurrence of voices which crisscross the discursive practices in these papers on the theme. This qualitative study on an inductive and interpretive basis shows the need for reflection on sexual diversity in the school context, based on educational practices about sexuality.
\end{abstract}

Keywords: sexual diversity, education, discursive practices.

* Mestrando do Programa de Pós-Graduação em Educaçấo, Linguagens e Tecnologias da Universidade Estadual de Goiás. E-mail: aldoff25@hotmail.com

** Doutora pelo Programa de Pós-Graduação em Estudos da Linguagem (PPgEL), do Centro de Ciências Humanas, Letras e Artes (CCHLA), da Universidade Federal do Rio Grande do Norte (UFRN). E-mail: ivonetebs@live.com 


\section{Palavras iniciais}

Sonho com o intelectual destruidor das evidências e das universalidades, que localiza e indica nas inércias e coaçóes do presente os pontos fracos, as brechas, as linhas de força; que sem cessar se desloca, náo sabe exatamente onde estará ou o que pensará amanhá, por estar muito atento ao presente...

(Foucault)

A epígrafe foucaultiana escolhida para iniciar este texto coloca em evidência o modo como um dos pensadores do pós-estruturalismo posicionase sobre a questão da sexualidade e das "verdades instituídas". Assim, afirmase que todas as nossas novas descobertas, todas as nossas (des)construçóes de saberes e de valor têm pouca possibilidade de pensamento generalizado. Essa atitude pós-estruturalista, que se organiza por movimentos e deslocamentos que, às vezes, desestabilizam nossas verdades e "nossas certezas" (MEYER \& SOARES, 2005), pode ser considerada pertinente estar presente no pensamento das instituiçóes educadoras e dos educadores, tendo em vista que, na contemporaneidade, os estudos em relação às diferenças vêm recebendo considerável destaque entre alguns pesquisadores da área das Ciências Humanas. Judith Revel (2005), uma estudiosa francesa, ao analisar os "conceitos essenciais" de Michel Foucault, assevera:

Foucault transforma a sexualidade num objeto de pesquisa específico, já que, insistindo no fato de que o poder se articula sempre sobre discursos de "veridicção", isto é, dos "jogos de verdade", as relaçôes com o dizer verdadeiro, em nenhum outro campo é tăo evidente quanto no da sexualidade: pertencemos a uma civilização na qual se exige aos homens dizerem a verdade a respeito de sua sexualidade para poder dizer a verdade sobre eles mesmos. (REVEL, 2005, p. 80)

As questôes de diversidades racial, social, étnica, cultural e sexual não deveriam ser mais motivos para a promoção de práticas discriminatórias no espaço escolar, mas ainda se encontra quem, infelizmente, tem prestigiado essas práticas. Assim sendo, são várias as possibilidades e situaçóes que fazem ocorrer com maior ou menor frequência as discriminaçóes referentes às sexualidades. Essas práticas discriminatórias relacionadas à diversidade sexual têm fomentado a homofobia. Nesse sentido, toma-se o conceito de homofobia como "uma manifestação arbitrária que consiste em designar o 
outro como contrário, inferior ou anormal, o que, na sua diferença, torna-se irredutível e o sujeito é colocado em outro lugar fora do universo comum dos humanos" (BORRILLO, 2009, p. 15).

São duas indagaçôes fundamentais movedoras deste texto. Primeira: é possível haver práticas educativas na escola sobre a diversidade sexual? Segunda: é papel do professor problematizar em sala questóes concernentes à sexualidade, promovendo debates esclarecedores com seus alunos e alunas, tendo como intuito (des)construir saberes e discursos de verdades sobre o reconhecimento da diversidade sexual nas escolas?

Acredita-se na importância de práticas educativas acerca da sexualidade no âmbito escolar por parte dos educadores, uma vez que o sujeito professor é considerado em sala de aula um condutor discursivo e formador de opiniōes, pois seu discurso pode circular em vários contextos sociais existentes na sociedade moderna. Reconhece-se que a escola "é uma agência importante na constituição de quem somos e seus discursos podem legitimar outros sentidos sobre quem podemos ser [...]" (MOITA LOPES, 2008, p. 125).

Nesse sentido, faz-se importante problematizar sobre as maneiras de ser e estar em relação ao contexto educativo. Para isso, busca-se nas leituras de Louro (2001, 2004, 2010), Michel Foucault (2001a; 2001b), Moita Lopes (2008), dentre outros, algumas passagens capazes de estimular discussóes e proporcionar reflexóes acerca do assunto emergente no cenário deste presente estudo.

Sendo o principal foco deste estudo, de base qualitativa interpretativa, a diversidade sexual no contexto escolar, foram selecionados na literatura estudada três artigos, para se examinarem os pontos em comum apontados, considerando a recorrência de vozes que entrecruzam suas práticas discursivas acerca da temática. Com este intuito, a seleção e a análise dos fragmentos apresentados, no item da análise dos dados, dáo-se no sentido de problematizar as questóes que permeiam as sexualidades e os efeitos de sentido materializados nos recortes discursivos analisados. Apresenta-se a seguir um breve resumo dos estudos escolhidos para a análise.

O primeiro artigo analisado é de Célio Lucion, Homofobia na escola pública. Esse estudo tem como objetivo propor discussóes e debates sobre o tema através do Plano de Desenvolvimento da Escola (PDE), com o fim de estimular o reconhecimento da diversidade sexual na escola, estimular a eliminação da homofobia, ou, pelo menos, uma possível diminuição. $\mathrm{O}$ 
professor, em seu trabalho cotidiano, deve promover reflexóes para diminuir o "silenciamento" sobre a prática preconceituosa e discriminatória contra os homossexuais. Em sua proposta, o autor defende uma educação continuada em que as práticas no cotidiano escolar sejam entendidas e respeitadas na e para a diversidade sexual e afetiva. Através do PDE, é possível que as universidades e as escolas dialoguem e que o conhecimento produzido seja sistematizado e posto em prática juntamente com a comunidade escolar (discentes e docentes). $\mathrm{O}$ autor apresenta seu trabalho em três partes, sendo elas, respectivamente: exposição do tema para os docentes; intervenção na escola através de mural na sala dos professores; exposiçáo do tema para os discentes.

O segundo trabalho escolhido, Enfocando a homossexualidade nas escolas, é da professora Celina Célia Furlan Correia, que teve como orientadora a professora Virgínia Iara de Andrade Maistro, da Universidade Estadual de Londrina (UEL). Esse trabalho tem como objetivo coletar e analisar dados de um questionário em que alunos, alunas e professores são inquiridos sobre questóes acerca da sexualidade e homossexualidade. A proposta, segundo a autora, "é esclarecer as dúvidas e corrigir ideias préconcebidas que não tinham fundamentação científica" (Correia, 2010, p. 1). A autora traz algumas consideraçóes sobre a sexualidade, a educação sexual, com a seguinte problematização: "Por que é necessário trabalhar a homossexualidade na escola?” (CORREIA, 2010, p. 7).

O terceiro e último trabalho para análise é das professoras Rita Oliveira e Clarilza Sousa, tendo como título Homossexualidade: representaçóes sociais de sexualidade para professores cuiabanos. Nesse artigo, o objetivo é identificar o que os professores pensam sobre a sexualidade e a educação sexual nas escolas. $\mathrm{O}$ referido trabalho torna-se relevante porque propóe reflexóes acerca do tema, com questionamentos em relação aos professores, suas crenças, seus pensamentos e ideias a respeito da educaçáo sexual e da sexualidade. $\mathrm{Na}$ análise das autoras, foram percebidas algumas práticas discriminatórias recorrentes em relação aos docentes, evidenciadas por discursos que apresentavam características e visóes estereotipadas.

Observa-se, nestes três estudos, que professores são vistos como profissionais com papéis relevantes no âmbito de sua atuação, pois sua história profissional foi, ao longo do tempo, permeada de respeito, autoridade e saberes. Convém observar que, ao longo da história, a figura desses "mestres" era marcada por hierarquias, sendo o professor o detentor do conhecimento 
e o aluno apenas um receptor, que não questionava nada, compreendido como uma "tábula rasa", com um saber verticalizado. A escola é o espaço físico e simbólico desses profissionais, e as suas relações nesse locus são reiteradas, negociadas e, algumas vezes, não compreendidas.

Os mecanismos de controle social e de exclusão escolar podem ser extremamente aguerridos contra o aluno homossexual, pois essa identidade contraria o propagado, o posto, o fabricado, o modelado e aceito pela sociedade. Nesse sentido, o discurso do professor passa a ser importante para a "reproduçáo" ou "desconstrução" de supostos modelos, dados como "certos" ou "errados". Foucault, em suas reflexôes sobre diversidade, alerta para os "discursos que podem matar [...], discursos que fazem rir". Estes "[...] discursos de verdade que fazem rir e que têm o poder institucional de matar são, no fim das contas, numa sociedade como a nossa, discursos que merecem um pouco de atenção" (FOUCAULT, 2001b, p. 8).

\section{Um breve percurso histórico sobre a homossexualidade}

Busca-se, aqui, inspiração na perspectiva filosófica de Michel Foucault e em estudos de outros autores mencionados. Michel Foucault (2001a) afirma que o sujeito homossexual só surge discursivamente a partir da publicação, em 1870, do artigo Archiv für Neurologie, do médico psiquiatra e neurologista alemão, Carl Westphal. Nos séculos anteriores, até o século XIX, não existia a "categoria homossexual" ou o "sujeito homossexual". Embora alguns afirmem que a homossexualidade remonta de muito tempo, é importante observar que o "sujeito homossexual" existe somente há dois séculos (FOUCAULT, 2001a). Desse modo, o sujeito homossexual torna-se uma "categoria", sendo uma "identidade construída" e náo descoberta.

Esta categoria é vista como "desviante" e "perversa": algo de natureza "anormal", algo patológico; isto é, observa-se que as expressôes linguísticas "desviante" e "perversa" parecem produzir efeitos sobre esse indivíduo homossexual, que passa a ser não só um pecador, doente ou criminoso, tornase uma categoria identitária com sua "sexualidade descrita, compreendida, explicada, regulada, saneada, educada e normatizada" (LOURO, 2004, p. 27). Assim, nomear a homossexualidade como distúrbio, perversáo, como uma doença a ser tratada, parece explicar algumas das práticas discursivas materializadas em certos atos de discriminação percebidos em nossa sociedade. 
Com o surgimento do termo "homossexualismo", criado a partir do substantivo "homossexual", pelo jornalista e escritor húngaro, o notável Karl-Maria Kertbeny (1824-1882), no século XIX, é possível afirmar que esse sujeito constituído como homossexual torna-se um "tipo aberrante de ser humano pervertido". Como demonstra Foucault (2001a), o homossexual do século XIX torna-se uma "patologização", deve-se tratá-lo, e, ainda,

torna-se uma personagem: um passado, uma história, uma infância, um caráter, uma forma de vida; também é morfologia, com uma anatomia indiscreta e, talvez, uma fisiologia misteriosa. Nada daquilo que ele é, no fim das contas, escapa à sua sexualidade. Ela está presente nele todo [...] [é]-lhe consubstancial, náo tanto como pecado habitual, porém, como natureza singular. (FOUCAULT, 2001a, p. 43)

Diante desse posicionamento de Foucault, é possível afirmar que o sujeito homossexual tem discursivamente seu lugar na existência a partir de um árduo caminho de "crime", perversão, rumo à suposta "legalidade" e "sanidade". Outros estudiosos, como Lionço e Diniz (2009), Reis e Ribeiro (2002), Rosemberg (1985), preocupados com questóes sobre sexualidade, demonstram em seus estudos como é vista e percebida a diversidade sexual nos dias atuais, principalmente em referência à cultura judaico-cristã ocidental. Para esses pesquisadores, a sexualidade vai de encontro às práticas discursivas higienistas, essencialistas e naturalistas, até uma sexualidade controlada, vigiada e regulada para o bem comum. Dessa maneira, entendese que é através do "crime" em que o homossexual está inserido que ele se constitui como "antinatural", pois está fora da "ordem natural" defendida pela religiosidade judaico-cristã. Assim, a procriação está ameaçada e, por conseguinte, esse sujeito deve ser satanizado e expurgado da sociedade.

Observam-se, no contexto dos séculos XVIII e XIX, práticas sociais marcadas por discursos médicos higienizadores da "(homo)erótica", promovendo uma sexualidade marcada pelos aspectos biologizantes. Nesse sentido, Souza (1997), em convergência com as propostas foucaultianas, assevera que a medicina torna-se uma propagadora de saberes científicos em que o humano é deixado de lado (deslocado) para o aspecto animal. Ou seja, o sexo passa a ser concebido de forma naturalizada/natural e sua única funçáo é a procriação/função reprodutora. Foucault (2001) assinala que, na modernidade, a sexualidade humana esteve/está sob a suposta ameaça de ser dominada por processos patológicos. $\mathrm{Na}$ medida em que a medicina une a 
sexualidade à reprodução, força "o distanciamento entre a sexualidade e a subjetividade" (SOUZA, 1997, p. 14).

Assim, o sujeito homossexual é compreendido como um dos excêntricos (aquele que sai do centro) que subverte o modelo de procriaçáo propagado pela igreja, pela sociedade, (trans)formando-se em sujeito ilegal, transeunte da clandestinidade. Por isso, entendemos que a "sexualidade está relacionada ao poder e ao político” (SOARES, 2003, p. 146).

\section{O que é diversidade sexual?}

As discussóes acerca da diversidade sexual, identidade cultural e sexualidade têm início no começo da década de 1980. No Brasil, essas discussóes só emergem na metade dessa década, com o surgimento dos movimentos sociais e das Ciências Sociais (BRASIL, 2007). A partir dos estudos desta ciência, foi possível desmistificar as visóes essencialistas, com o desenvolvimento de vários estudos e análises sobre as múltiplas relaçóes de classe, raça/etnia, gênero.

A diversidade sexual, neste estudo, é entendida como a pluralidade das relaçóes afetivas e sexuais entre pessoas do mesmo sexo. $\mathrm{O}$ não reconhecimento dessa diversidade no espaço escolar pode representar um cerceamento do sujeito, e, assim, os direitos universais do cidadão passam a não ser respeitados. A Lei de Diretrizes e Bases da Educação (LDB) postula em seu artigo terceiro que o ensino deve ser ministrado em consonância com a diversidade e o respeito: "respeito à liberdade e apreço à tolerância" (inciso IV). No entanto, o que esse artigo referenda no inciso citado é algo possivelmente distante do âmbito escolar.

A escola torna-se uma formadora de subjetividades e sexualidades, tendo um papel relevante na sociedade, porque em seu espaço existe uma construção do que seja ideal e "normal". Em relação a essa "normalidade", à classificação do sujeito como "normal" ou "anormal", as palavras de Thoma (2005) são oportunas:

Normalidade e anormalidade são questóes centrais nos debates sobre inclusão e exclusão à medida que as representaçóes e discursos que circulam com maior predominância no circuito cultural sáo aqueles que dividem os sujeitos entre normais e anormais, atribuindo um juízo de valor pelo qual os primeiros estâo em vantagem sobre os segundos. (THOMA, 2005, p. 1) 
Pode-se dizer que, depois da família, a escola é transmissora e formadora de valores, e esses mesmos valores são cobrados e reproduzidos pela família, sociedade e Estado. Dessa forma, os valores são reiterados, repetidos e reelaborados nessa sistemática de exclusáo e silenciamento das diversidades sexuais em seu espaço (escolar), em que "tolerar" e "gerir" torna-se mais fácil que "reconhecer" e "respeitar" o diferente, ou seja, aquele localizado na zona fronteiriça.

A instituição escolar deve estar atenta ao "intolerável" em seu espaço, para que os questionamentos sejam trazidos à baila e as formas identitárias sejam discutidas, possibilitando, assim, uma criticidade sobre as maneiras de ser dos indivíduos na sociedade (MOITA LOPES, 2006). Embora a escola proponha discussóes sobre sexualidade no viés da heteronormatividade, em que relaçốes afetivas e sexuais são ensinadas através do ajustamento de identidades e corpos heterossexuais, nota-se uma prevalência do sistema de hierarquização das identidades. Portanto, é importante refletir sobre o posicionamento da Secretaria de Educação Continuada, Alfabetização e Diversidade (Secad/MEC), referente ao reconhecimento da diversidade sexual:

É muito recente a inclusão das questóes de gênero, identidade de gênero e orientaçấo sexual na educaçấo brasileira a partir de uma perspectiva de valorização da igualdade de gênero e de promoção de uma cultura de respeito e reconhecimento da diversidade sexual. [...] $\mathrm{Na}$ agenda política em geral e na educacional em particular, a inclusão de tais temáticas, a partir desse ponto de vista, é algo ainda em fase inicial de construção. (BRASIL, 2007, p. 11)

Tendo como pressupostos as recentes discussóes e inclusóes das questóes de gênero no currículo da educação brasileira, é importante ressaltar as contribuiçóes das Ciências Humanas, pois, a partir destas, foi possível uma implementação de políticas públicas na e para a educação. Dentre algumas políticas públicas destaca-se a elaboração/distribuição dos Parâmetros Curriculares Nacionais/PCNs (MEC/Secretaria de Educação Fundamental, 1998), que trazem os Temas Transversais, incluindo a sexualidade entre os temas de estudo e promovendo discussóes e reflexôes nas escolas.

Ainda que haja limitaçóes acerca das reflexôes educativas sobre diversidade sexual na proposta dos PCNs, eles produzem em seus discursos sentidos que traduzem uma preocupação em propor a discussão em sala de 
aula, promovendo um espaço de tolerância, para uma diversidade sexual respeitada. Nesse sentido, sobre o papel do professor e professora, e da escola, os PCNs concluem:

A escola deve informar e discutir os diferentes tabus, preconceitos, crenças e atitudes existentes na sociedade, buscando, se não uma isençẫo total, o que é impossível de se conseguir, uma condição de maior distanciamento pessoal por parte dos professores para empreender essa tarefa. [...] $\mathrm{O}$ professor transmite valores com relaçáo à sexualidade no seu trabalho cotidiano, na forma de responder ou não às questôes mais simples trazidas pelos alunos. É necessário então que o educador tenha acesso à formação específica para tratar de sexualidade com crianças e jovens na escola, possibilitando a construçáo de uma postura profissional e consciente no trato desse tema. O professor deve então entrar em contato com questóes teóricas, leituras e discussóes sobre as temáticas específicas de sexualidade e suas diferentes abordagens [...] ter acesso a um espaço de reflexáo sobre valores e preconceitos dos próprios educadores envolvidos. [...]. (BRASIL, 1998, p. 83-84)

Percebe-se nessa passagem a ênfase dada pelos PCNs às questões de cunho discriminatório na escola. Esta agenciadora (a escola) pode legitimar identidades limitadas e aprisionadoras, favorecendo a construção de padrôes normalizadores e homogeneizadores de corpos construídos por discursos, como parte de uma lógica monocultural. Enfim, como também indica Moita Lopes (2008, p. 134), a lógica monocultural se associa

[...] a um modo de explicaçáo da vida social voltado para a mesmice (somos todos iguais), ou seja, somos guiados por significados homogêneos que produzem uma única interpretação. Nessa lógica, opera na direção da heterogeneização e da diferença, em que ressalta a nossa construção social, nas práticas discursivas, sob as redes de poder.

A partir da concepçáo do linguista, imaginamos uma escola que pensa em seu aluno não como um ser desligado do espaço em que está inserido, mas aquele que tem a sua sexualidade em plena relação com a sua subjetividade, não sendo fabricado nas instâncias sociais como um ser assexuado, destituído de sua afetividade em casa ou fora da escola. Os alunos e alunas devem ser respeitados pelas diferenças sexuais, para não serem obrigados a "despir-se de sua(s) sexualidade(s)" como se fosse algo "postiço" retirado a qualquer hora (LOURO, 2004). 


\section{Análise dos dados}

Neste item, apresentam-se os trechos dos artigos referidos na introdução deste estudo, selecionados para a análise. Os autores desses trabalhos são denominados por (P1): professor-pesquisador 1; (P2): professor-pesquisador 2; e (P3): professor-pesquisador 3. A análise, como foi dito anteriormente, é advinda dos seguintes trabalhos: Homofobia na escola pública, do pesquisador Célio Lucion (2011); Enfocando a homossexualidade nas escolas, da pesquisadora Celina Célia Furlan Correia (2010); Homossexualidade: representaçóes sociais de sexualidade para professores cuiabanos, das pesquisadoras Rita Oliveira e Clarilza Sousa (2011). Na ordem estabelecida, P1 é do sexo masculino, professor de História no Estado do Paraná; P2 é do sexo feminino, professora na cidade de Londrina, Paraná; as outras pesquisadoras, P3, são do sexo feminino, professoras do Ensino Superior no Estado de Mato Grosso. Os trechos estão distribuídos em quatro categorias de análise, a seguir:

\section{Silenciamento acerca do preconceito sexual}

Nessa primeira categoria de análise, verifica-se nas sequências discursivas dos professores pesquisadores a importância de principiar as discussóes sobre a diversidade sexual nas escolas.

(1) P1: [...] muitos professores não assumem as discriminaçōes e preconceitos em relação aos homossexuais, ao considerarem que expressóes de conotação negativa em relação a estes seriam brincadeiras, coisas sem importância.

(2) P3: [...] aspectos da manifestação da sexualidade, como a homossexualidade, mais frequentemente destacada entre os assuntos, foi apresentada com dificuldades pelos docentes, ainda que admitam a sua existência no âmbito da escola.

Percebe-se em P1 o silenciamento por parte dos professores, a discriminação e o preconceito existentes nos espaços escolares. A náo discussão por parte do professor pode promover uma educação alienante, ou seja, o sujeito emancipado constrói e reproduz uma escola excludente, controla e despe as sexualidades dos alunos e alunas através de suas práticas discursivas. Se os professores "silenciam" acerca da homossexualidade, é possível afirmar que esse silenciamento ocorra por falta de abordagens pedagógicas e 
teóricas nos cursos de formação de professores e na educação continuada, ou seja, em todos os níveis de ensino (LEÃO, 2009; OLIVEIRA, 2007). Daí a importância das discussóes sobre a sexualidade, uma vez que o profissional da educação, sobretudo o de língua materna, "transita" em vários usos de códigos e linguagens.

Na sequência discursiva de P3, é possível perceber que professores têm dificuldades em propor discussóes reconhecedoras da diversidade sexual. P1 dialoga com P3 quando instiga discussóes sobre as relaçóes afetivas e sexuais dos alunos que estão sendo silenciadas, ignoradas e "toleradas". Em relação à escola, percebe-se que o seu espaço não se humaniza, ensina ou promove uma relação de respeito, mas, sim, há muita intolerância e desrespeito com o aluno, tendo este sua "cidadania mutilada" (SANTOS, 1987).

\section{Visão da escola sobre a sexualidade apontada discursivamente nos artigos}

Nesta segunda categoria, apontam-se os resultados de discussóes sobre a possibilidade de questionamento acerca da sexualidade no âmbito escolar.

P1: [...] A escola, seja ela pública ou privada, se mantém fechada a respeito da homossexualidade em suas dependências, buscando repelir, excluir o diferente, bem como tratar a homossexualidade como aberração ou doença.

P2: [...] Os professores e a equipe pedagógica, por sua vez, fizeram a sua parte, trabalhando e orientando os alunos em questóes que surgiram em suas aulas e dentro da escola, de uma forma clara e simples, desmistificando a homossexualidade [...].

P3: [...] certa intranquilidade dos docentes para lidar com o tema Educaçáo Sexual, escondidos entre o conflito de ter que ensinar $o$ assunto, pois se trata da sexualidade enquanto tema transversal, e a necessidade vivenciada no cotidiano da escola implorando pela quebra do silêncio.

Observa-se que P1 traduz as ideias contidas nos PCNs, a seguir: “[...] Por vezes a escola realiza o pedido, impossível de ser atendido, para os alunos deixarem suas sexualidades fora dela [...]" (BRASIL, 1998, p. 78). Pode-se afirmar que, pelo fato de não abordar as sexualidades existentes em 
seu espaço, a escola está impedindo o acesso do aluno ao direito básico à educação, proposto pela constituição.

Em P1 e P3, percebe-se que a temática da diversidade sexual, sobretudo no que tange à homossexualidade, é de difícil abordagem pela escola e professores. As vozes entrecruzadas nos discursos afirmam o "fechar" da escola para a discussão da homossexualidade. Observa-se também um reconhecimento, evidenciado em $\mathrm{P} 3$, quanto à "quebra do silêncio", presente no espaço escolar e nos contextos discursivos. Ou seja, a escola como formadora social (espaço) passa a discutir o assunto a fim de promover uma tomada de posição (contexto). É importante observar em P2 e P3 a confirmação da dificuldade existente em abordar a temática da diversidade sexual na escola, pois o profissional da educação não se sente preparado para tal atuação. Apesar das dificuldades em relação a essa abordagem, a escola tem se preocupado em orientar os alunos para a desmistificação da homossexualidade.

Diante da análise realizada, é importante destacar, nos trechos acima, as evidências das contradiçóes discursivas, uma vez que afirmam que a escola "exclui", "repele", "intranquiliza". Não obstante, "orienta", "desmistifica" e "implora pela quebra do silêncio".

\section{A homofobia permeia as relaçốes no contexto escolar?}

Aqui, compreende-se que a homofobia, como está apresentada nos recortes de P1, P2 e P3, é realmente uma "produção histórica cultural", sendo confirmada em Foucault, nos estudos sobre sexualidade, uma vez que a "categoria homossexual", segundo o pensador francês, surge no século XIX. Antes disso não poderia haver a homofobia como é conhecida na contemporaneidade, pois o sujeito homossexual, discursivamente, não existia antes do século citado.

P1: A homofobia é uma produção histórica cultural em que teorias são criadas, defendidas [...] e a escola inserida nessas condiçôes históricas as reproduz e reafirma o que a sociedade exige dela.

P2: [...] Oprofessor, em sua formação acadêmica, não apreende conhecimentos básicos para lidar com estas situaçôes que poderiam ser contornadas de uma forma natural. [...] a escola prolonga a homofobia cultural da sociedade, com conceitos retrógrados de ordem moral e familiar. 
P3: [...] comportamentos são legitimados simbolicamente associados a chacotas e piadinhas que os colegas fazem, enquanto os professores admitem que sejam brincadeiras dos colegas. [...] é brincadeira, não se configura como algo agressivo. [...] xingamentos tomam a forma de divertimento para os colegas $[. .$.$] .$

P1 afirma que a escola tem um papel relevante na propagação de discursos e práticas que podem propor uma discussão (ou náo) em torno das práticas discriminatórias. Na medida em que há na sociedade a exigência de modelos valorizados e identificados com a sistemática binária, essas práticas discriminatórias são hierarquizadas e valorizadas. Dessa forma, a escola está permeada de discursos norteados por relaçóes dicotomizadas de homem/mulher, "normal/anormal", menino/menina, branco/negro, heterossexual/homossexual etc. Na prática social "valorizada", "reproduzida" e "reafirmada", pressupóe-se a existência de uma hierarquia entre a ordem estabelecida nos discursos. O primeiro elemento dessa dicotomia (homem, normal, menino, branco, heterossexual etc.) é concebido como superior em relação ao segundo (mulher, anormal, menina, negro, homossexual), sendo, portanto, este último considerado nessa lógica como algo fora do padrão aceito na sociedade.

Em P2 verificam-se discursos inter-relacionados quando o pesquisador se refere à historicidade da homofobia e da escola como "propagadora discursiva”. Ressalta-se a não apreensão, por parte do professor, de pressupostos teóricos e pedagógicos para a desconstrução de práticas homofóbicas. $\mathrm{O}$ professor e a escola que não propóem uma educação valorizada para e pela cidadania estão legitimando identidades e práticas que perpetuam a desvalorização do outro, daquele imbricado na fronteira, daquele fora da norma, ou seja, do diferente, do "estranho".

É possível afirmar que P1, P2 e P3 dialogam em seus trabalhos, no que diz respeito à homofobia como um construto cultural e à escola como espaço de reprodução de práticas discriminatórias. Segundo Louro (2010, p. 68), "a negação dos homossexuais no espaço legitimado da sala de aula acaba por confiná-los às gozaçóes e aos insultos dos recreios e dos jogos, fazendo com que, deste modo, jovens gays e lésbicas só possam se reconhecer como desviantes, indesejados ou ridículos".

Para analisar P3, é importante observar a afirmação de Louro (2010), acima, pois verifica-se que ao não serem questionadas atitudes e práticas discriminatórias no espaço escolar, este espaço reforça, de uma 
maneira "velada", através do corpo docente, o "preconceito naturalizado". Se essas práticas que discriminam forem vistas como brincadeiras, tidas como naturais, serão olvidadas, promovendo-se, talvez, uma "pedagogia da exclusão".

\section{Como abordar a temática "sexualidade" na escola?}

Nessa última categoria de análise, os fragmentos traduzem a necessidade de abordar o tema "sexualidade" no espaço escolar.

P1: Uma abordagem histórica "vista de baixo", que vise incluir a participação de "outros sujeitos", pautada por "relaçôes de poder", deve necessariamente se aproximar de outras áreas do conhecimento humano, desconsideradas em outras épocas.

P2: Abordar o tema homossexualidade nas escolas [...] implica planejamento e açóes pedagógicas sistemáticas. Não se trata de palestras, semanas especiais, de cartazes pregados nos murais, mas sim de um canal permanentemente aberto para que as questöes sobre a sexualidade possam ser discutidas com as crianças e adolescentes de maneira séria, clara e ampla.

P3: [...] faz-se necessário que sejam abertos espaços de discussöes e reflexóes sobre sexualidade, para que temores sejam confessados e receios dissipados.

No trecho acima, P1 propóe uma abordagem da sexualidade por meio de uma "arqueologia", ou seja, uma discussão que privilegie outros sujeitos e discursos no espaço das escolas. Dessa maneira, a abordagem feita através da interdisciplinaridade é válida e possível, porque deixará de valorizar a concepção "naturalizante" e "essencialista" (JUNQUEIRA, 2009). Uma identidade inferiorizada na história, reforçada por narrativas de vitimizaçôes, tem servido para a legitimação de alguns grupos (tidos como melhores e superiores) que se sobrepóem aos outros (tidos como inferiores). Fabricase, assim, um sujeito destituído de sexualidade, uma vez que a "sexualidade compulsória" passa a ser a heterossexual, ou seja, nasce-se com a obrigação de seguir o modelo heteronormativo. É possível, talvez, afirmar que abordar as sexualidades de forma aberta, em que as múltiplas identidades sejam (re) conhecidas no espaço escolar, pode provocar "temores" nos professores, uma vez que em suas práticas educativas evidenciarão o seu lugar/estar no mundo, através da atuação profissional se farão existentes/presentes. 
Em P1, P2 e P3, pode-se afirmar que as vozes se entrecruzam, uma vez que se propóe uma sistemática teórica e pedagógica nas abordagens do professor em seu cotidiano. Nessa perspectiva, a escola, a educação e o currículo passam a ser um espaço para o exercício da cidadania e do respeito, podendo estes ser reconhecidos e ressignificados. Reconhecidos porque estavam "silenciados" e esquecidos. Ressignificados porque, a partir da reflexão crítica e pedagógica, pode ser possível que a escola consiga (des) construir e (res)significar a prática profissional em sala de aula, ou seja, (trans)formar o tido como "anormal" (fora da norma) para a afirmação da diversidade sexual como estratégia de reconhecimento.

\section{Palavras finais}

Retoma-se, para finalizar este texto, a ideia que mais fortemente nos motivou a escrevê-lo: tentar colocar em destaque a importância de se empreenderem reflexóes no que concerne à temática da diversidade sexual no contexto escolar. Assim, a partir dos ensaios de análise nesse breve artigo, foi possível concluir que práticas educativas sobre a sexualidade constituem uma abordagem que se apresenta de difícil acesso, talvez ainda uma utopia.

A escola corre o risco de reforçar práticas homofóbicas em seu espaço pelo fato de não debater, problematizar e desconstruir discursos tidos como verdadeiros, relacionados às sexualidades. Esses discursos de verdades não desvinculados do senso comum e questionados podem normatizar, gerir, hierarquizar e controlar as sexualidades dos discentes. Dessa maneira, a escola e professores podem deixar de reconhecer as pluralidades existentes nesses espaços físicos e simbólicos, permeados pelas práticas sociais.

Ainda correndo o risco de ser prescritivo, afirma-se, mais uma vez, que sem a implementação de políticas públicas e o compromisso e atenção de instituiçôes responsáveis pelos cursos de formação inicial e continuada de professores, no sentido de abordarem a temática das diversidades existentes na sociedade, será difícil a construção do sujeito emancipado, liberto das amarras vitimizadoras que discriminam, diminuem e mutilam as características subjetivas e culturais do alunado (LOURO, 2010; SANTOS, 1987).

Interrompe-se, aqui, esta escrita, com o convite a todos os professores a trabalhar em direçấo à promoção do "reconhecimento" das diferenças... Que problematizem e discutam as opinióes e práticas pedagógicas machistas, 
sexistas e binárias, construindo e valorizando todas as formas de identidades culturais e sexuais, estando atentos ao "intolerável", e desconfiando dos gestos que o espaço escolar supostamente promove de acolhimento, quando, na verdade, pode reforçar o discurso do "silenciamento" e as práticas homofóbicas.

O resultado deste estudo permitiu, também, perceber que aceitar o desafio de pesquisar em outras disposiçóes epistemológicas pode nos dar a possibilidade de nos constituir como pesquisadores, com olhares direcionados aos novos arranjos sociais. No dizer de Fischer (2005, p. 139) "[...] nossas produçôes acadêmicas precisam respirar novos ares, ares artistas, ares de acontecimento, de modo que aquilo que lemos, e aquilo que escrevemos, de alguma forma tenha a característica de um advento".

\section{Referências}

BORRILO, D. A homofobia. In: DINIZ, D.; LIONÇO, T. (Org.). Homofobia \& educação: um desafio ao silêncio. Brasília: UnB, 2009. p. $15-46$.

BRASIL. Lei n. 9.394, de 20 de dezembro de 1996 (Lei de Diretrizes e Bases da Educação Nacional/LDB). Disponível em: < http://portal.mec. gov.br/arquivos/pdf/ldb.pdf>. Acesso em: 15 jan. 2012.

BRASIL. Secretaria de Educação Fundamental. Parâmetros Curriculares Nacionais: terceiro e quarto ciclos. Apresentação dos temas transversais. Brasília: MEC/SEF, 1998. Disponível em: < http://portal.mec.gov.br/seb/ arquivos/pdf/ttransversais.pdf >. Acesso em: 10 jan. 2012.

BRASIL. PCNs. Pluralidade Cultural e Orientação Sexual. Brasília-DF. Disponível em: http://portal.mec.gov.br/seb/arquivos/pdf/livro102.pdf. Acesso em: 25 jan. 2012.

BRASIL. SECAD/MEC. Gênero e Diversidade Sexual na Escola: reconhecer diferenças e superar preconceitos. Brasília-DF: Cadernos Secad/MEC, 2007, p. 11. Disponível em: <http://portal.mec.gov.br/secad/arquivos/pdf/ escola_protege/caderno5.pdf>. Acesso em: 13 mar. 2012.

CORREIA, C. C. F. Enfocando a homossexualidade nas escolas. 2010. Disponível em: http://www.diaadiaeducacao.pr.gov.br/diaadia/diadia/index. php?PHPSESSID=201009221881216. Acesso em: 12 dez. 2010. 
FISCHER, R. M. Bueno. Escrita acadêmica: arte de assinar o que se lê. In: BUJES, M. I. E.; COSTA, M. V. (Org.). Caminhos investigativos III: riscos e possibilidades de pesquisar nas fronteiras. Rio de Janeiro: DP\&A, 2005. p. 117-140.

FOUCAULT, M. História da sexualidade: a vontade de saber. 14. ed. São Paulo: Graal, 2001a.v.1.

FOUCAULT, M. Microfisica do poder. 20 ed. Rio de Janeiro: Graal, 2004.

FOUCAULT, M. Os Anormais: curso no Collège de France. São Paulo: Martins Fontes, 2001b.

JUNQUEIRA, R. D. Políticas de educação para a diversidade sexual: escola como lugar de direitos. In: DINIZ, D.; LIONÇO,T. (Org.). Homofobia \& educação: um desafio ao silêncio. Brasília: Unb, 2009. p. 161-193.

LEÃO, A. M. C. Estudo analítico-descritivo do curso de Pedagogia da Unesp de Araraquara quanto à inserção das temáticas de sexualidade e orientaçáo sexual na formação de seus alunos. 350f. Tese (Doutorado em Educação Escolar) Universidade Estadual Paulista, Faculdade de Ciências e Letras, Araraquara, 2009.

LIONÇO, T.; DINIZ, D. Homofobia, silêncio e naturalização: por uma narrativa da diversidade sexual. In: LIONÇO, T.; DINIZ, D. (Org.). Homofobia \& educação: um desafio ao silêncio. Brasília: UnB, 2009. p. 4272.

LOURO, G. L. Um corpo estranho: ensaios sobre sexualidade e teoria queer. Belo Horizonte: Autêntica, 2004.

LOURO, G. L. Gênero, sexualidades e educação: das afinidades políticas às tensōes teórico-metodológicas. Educ.rev., Belo Horizonte, n. 46, 2007.

LOURO, G. L. Gênero, sexualidade e educação: uma perspectiva pósestruturalista. 11. ed. Rio de Janeiro: Vozes, 2010.

LÚCION, C. Homofobia na escola pública. Disponível em: <http://www. diaadiaeducacao.pr.gov.br/portals/pde/arquivos/981-4.pdf >. Acesso em: 1 nov. 2011.

MEYER, D. E. E.; SOARES, R. F. Modos de ver e de se movimentar pelos "caminhos" da pesquisa pós-estruturalista em Educação: o que podemos aprender com - e a partir de - um filme. In: COSTA, M. V.; BUJES, M. 
I. E. (Org.). Caminhos investigativos III: riscos e possibilidades de pesquisar nas fronteiras. 1. ed. Rio de Janeiro: DP\&A, 2005. p. 23-44.

MOITA LOPES, L. P. Identidades fragmentadas: a construção discursiva de raça, gênero e sexualidade em sala de aula. Campinas: Mercado de Letras, 2006.

MOITA LOPES, L. P. Sexualidades em sala de aula: discurso, desejo e teoria queer. In: MOREIRA, A. F.; CANDAU, V. M. (Org.). Multiculturalismo: diferenças culturais e práticas pedagógicas. 3. ed. Rio de Janeiro: Vozes, 2008.

OLIVEIRA, L. S. Representação de sexualidade que orienta práticas educativas no Brasil desde o final do século XIX. 81f. Dissertação (Mestrado em Educação e Cultura Contemporânea) - Universidade Estácio de Sá, Rio de Janeiro, 2007.

OLIVEIRA, R.; SOUSA, C. Homossexualidade: representações sociais de sexualidade para professores cuiabanos. Disponível em: http://www.ie.ufmt. br/semiedu2009/gts/gt13/ComunicacaoOral/RITA\%20APARECIDA\%20 PEREIRA\%20DE\%20OLIVEIRA.pdf. Acesso em: 10 jun. 2011.

REIS, G. V.; RIBEIRO, P. R. M. A orientação sexual na escola e os Parâmetros Curriculares Nacionais. In: RIBEIRO, P. R. M. Sexualidade e educação sexual: apontamentos para uma reflexão. São Paulo: Cultura Acadêmica Editora; Araraquara: Laboratório Editorial da FCL, 2002. p. 81-96.

REVEL, J. Michel Foucault: conceitos essenciais. Tradução de Maria do Rosário Gregolin, Nilton Milanez, Carlos Piovesani. Sáo Paulo: Claraluz, 2005.

ROSEMBERG, F. Educação sexual na escola. Cadernos de Pesquisa, São Paulo, n. 53, p. 11-19, maio 1985.

SANTOS, M. O espaço do cidadão. São Paulo: Nobel, 1987.

SOARES, R. Fica comigo, gay - o que um programa de TV ensina sobre uma sexualidade juvenil. In: LOURO, G. L. Corpo, gênero e sexualidade: um debate contemporâneo na educação. 4. ed. Petrópolis: Vozes, 2003. p. 136-148.

SOUZA, M. C. C. C. Sexo é uma coisa natural? A contribuição da psicanálise para o debate sexualidade/escola. In: AQUINO, J. G. (Org.). Sexualidade 
na escola: alternativas teóricas e práticas. 5. ed. São Paulo: Summus,1997. p. 11-23.

THOMA, A. S. Entre normais e anormais: invençóes que tecem inclusóes e exclusões das alteridades deficientes. In: PELLANDA, N. M. C.; SCHLÜNZEN, E.; SCHLÜNZEN, K. (Org.). Inclusão Digital: tecendo redes afetivas/cognitivas. Rio de Janeiro: DP\&A, 2005.

Recebido em: 30 maio 2012

Aceito em: 25 out. 2012 
